\title{
Expression of telomeric repeat binding factor 2 (TERF2) in childhood acute lymphoblastic leukemia
}

\author{
Lelamekala Vengidasan ${ }^{a}$, Choong Soo Sin ${ }^{a}$, Chen Kok Siong ${ }^{a}$, Kamariah Ibrahimª, \\ ${ }^{a}$ Paediatric Oncology Unit, University of Malaya Medical Centre, University of Malaya Cancer Research Institute, 50603 Kuala Lumpur, \\ Malaysia \\ ${ }^{b}$ Department of Biomedical Science, Faculty of Medicine, University of Malaya, 50603 Kuala Lumpur, Malaysia
}

Received 22nd December 2020 / Accepted 27th April 2021

\begin{abstract}
Acute lymphoblastic leukemia (ALL) is the most frequent cancer among children. Regardless of the advances in disease treatments, approximately 10-20\% of childhood ALL (cALL) have an incidence of relapse. Therefore, identification of additional prognostic variables is essential to provide specific therapeutic intervention for each patient. TERF2 is one of the main components of the shelterin complex (telosome) that plays a crucial role in the protective activity of telomeres. This research aims to investigate the expression level of TERF2 and its potential as a prognostic marker in cALL patients. 88 bone marrow samples and 6 peripheral blood were used to isolated cDNA samples. Real time PCR were used to study the gene expression of TERF2 in cALL. Results were standardized using B2M transcripts as an internal control. Relative quantification of the gene expression was calculated by using the delta-delta $\mathrm{Ct}$ method. TERF2 was up-regulated significantly in cALL patients compared to control samples of which pvalue $=0.002859,(\mathrm{p}<0.05)$. Over-expression of TERF2 was observed in TEL-AML1 subgroup of which $\mathrm{p}$-value $=0.0002,(\mathrm{p}<0.05)$. In contrast, under-expression of TERF2 was found in those having $B C R-A B L 1$ fusion transcripts of which $\mathrm{p}$-value $=0.0221,(\mathrm{p}<0.05)$. TERF2 also have found to have a better survival advantages for cALL patients. Over-expression of TERF2 is associated with good prognosis in cALL whilst under-expression is associated with poor prognosis in cALL patients. Measurement of TERF2 gene expression allows proper stratification of cALL subtypes into its respective prognostic indicator classification.
\end{abstract}

Keywords: acute lymphoblastic leukemia, childhood cancer, real-time PCR, telomeric repeat binding factor 2, TERF2

\section{INTRODUCTION}

Acute lymphoblastic leukemia (ALL) is the most common pediatric disease and occur in approximately one fourth of pediatric cancers (Kaatsch, 2010). Despite the remarkable treatment advances in the past decade and a cure rate of $80 \%$ in cALL through the effectiveness of risk-directed therapy developed and well-designed clinical trials, treatment failure remains a

\footnotetext{
*Author for correspondence: Kamariah Ibrahim, Paediatric Oncology Unit, University of Malaya Medical Centre, University of Malaya Cancer Research Institute, $50603 \quad$ Kuala Lumpur, Malaysia. Email kamariahibrahim2106@um.edu.my
}

formidable problem (Locatelli et al., 2012). Relapsed ALL ranks as the fourth most common childhood malignancy and has an overall survival rate of only $30 \%$. Alterations in the telomere maintenance have been associated with an adverse outcome in many cancers. Therefore, investigation of telomere length and its associated telomere complexes would lead us to understand 
its role in relapse in pediatric ALL (Avigad et al., 2007; Jones et al., 2012)

Mammalian telomeres are formed by tandem repeats of the TTAGGG sequence bound by a specialized six-protein complex known as shelterin, which has fundamental roles in the regulation of telomere length and telomere capping. The shelterin complex, also known as telosome consists of few interacting proteins; hTRT, TREF1, TERF2, POT1, EST1, TANK1, TANK2 and TEP (Lin et al., 2013; Kaminker et al., 2001; Neidle and Parkinson, 2003; De Lange, 2005). In this study, we focus on quantifying telomere repeat binding factor 2 (TERF2) gene expression in childhood ALL (cALL). TERF2 enhances the t-loop formation between telomere end and interacts with ataxia telangiectasia mutated (ATM) kinase from activating DNA damage signaling at functional telomeres (Stansel et al., 2001). Mutation in TERF2 leads not only to telomeric structure destruction but also to DNA damage, apoptosis, or senescence concomitantly (Van Steensel et al., 1998, Karlseder et al., 2002, Wang et al., 2004, Lechel et al., 2005). However, over-expression of TERF2 is associated with an increased rate of telomere shortening in primary human IMR90 fibroblasts without accelerating senescence (Karlseder et al., 2002, Martínez and Blasco, 2017).

The structure of telomeres and its maintenance genes were reported to be abnormal in many cancer cell lines (Jafri et al., 2016; Bernal and Tusell, 2018). TERF2 is over-expressed in several human tumors, such as skin cancer (Biroccio et al., 2006; Martínez and Blasco, 2017), hepatocarcinoma (Oh et al., 2005), carcinoma of the lung (Nakanishi et al., 2003) and breast carcinomas (Diehl et al., 2011; Nijjar et al., 2005) as well as colon cancer (Dong et al., 2010) which indicates that TERF2 may play a role in tumorigenesis. TERF2 expression has been reported to be increased, decreased or unchanged in other solid tumors (Diehl et al., 2011, Dong et al., 2010, Benhamou et al., 2016, Klapper et al., 2003).

Characterization of TERF2 mRNA overexpression in cALL TEL-AML1 subgroup is concordant with the findings from several research groups (Yeoh et al., 2002, van Delft et al., 2005, Gandemer et al., 2007). TERF2 is one of the 40 genes that are useful to discriminate ALL from
AML (van Delft et al., 2005). Hence, we would like to explore the potential value of TERF2 as a prognostic marker which may guide patients towards suitable therapy.

\section{MATERIALS AND METHODS}

\section{Patients and samples}

After informed consent, a total of 88 diagnostics bone marrow samples and 6 peripheral blood samples were obtained from children aged between 0.1 to 16 years diagnosed with de novo acute lymphoblastic leukemia (ALL). These patients were recruited from University of Malaya Medical Centre (UMMC) from January 2006 to December 2010 (Table 1). All leukemic cases were classified according to FAB criteria, characterized at cytogenetic level using G-banding karyotytping and screened by real-time polymerase chain reaction (PCR) for the presence of the most significant molecular fusion transcripts namely; $B C R-A B L 1$, E2A-PBX1, MLL-AF4 and TEL-AML1 as previously described in cALL (Cho et al., 2012). These samples also being immunophenotyped towards pre-B ALL markers such as CD34+ and CD19+ using flow-cytometer at the Clinical Diagnostic Lab, UMMC. TERF2 gene expression was also compared in five tumor samples (3 samples of Ewing sarcoma and a sample of hepatoblasma) and nine samples from other hematological malignancies (7 samples from AML and a sample from CML). Three healthy bone marrow and six healthy peripheral blood samples were used as control. All bone marrow samples were also being typed for CD34+ markers. Ethical approval was obtained from the University of Malaya Medical Centre Ethics committee for both the leukemia (MEC 2006/481.01) and solid tumour samples (MEC 2006/510.7).

\section{RNA extraction and preparation of cDNA}

Mononuclear cells were isolated from $2-3 \mathrm{ml}$ diagnostic bone marrow aspirate in $3 \mathrm{ml}$ EDTA tube by Ficoll-Hypaque density gradient centrifugation (GE Healthcare Life Sciences, USA). Total ribonucleic acid (RNA) was extracted by using TRIZOL method (Invitrogen, USA) according to the manufacturer's recommendation 
and stored at $-80^{\circ} \mathrm{C}$. As part of RNA quality assessment, archived samples were randomly selected, and RNA Integrity Number (RIN) were analysed on RNA 6000 Nano Labchip kit (Agilent Technologies, USA) using the Agilent 2100 Bioanalyser platform (Agilent Technologies, USA). Only RNA samples having RIN more than 8.5 were used for the study. Complementary DNA (cDNA) was synthesized from $1000 \mathrm{ng}$ of RNA by reverse-transcription PCR using Omniscript RT kit (Qiagen Inc., Valencia, CA). We also included a randomly picked cDNA sample as a minus reverse transcriptase control sample to check for DNA contamination in the RNA samples.

\section{Real-time PCR}

TERF2 gene expression (NCBI accession no: NM_005652.3) was assessed and quantified using real-time quantitative PCR on a Rotorgene ${ }^{\mathrm{TM}}$ 3000 real-time thermal cycler (Corbett Research, Australia). The amplification of TERF2 was performed with dsDNA intercalating dye, SYBRGreen using the following primers: forward primer for exon 6: 5' CAGGGAAGGAAGATAAACAGC $3^{\prime}$ and a reverse primer for exon 6: 5' CAATGGTGGTTGGAGGATTC 3'. Amplification of TERF2 cDNA produced a $93 \mathrm{bp}$ PCR product. Beta-2-microglobulin (B2M), a cytoskeletal protein involved in cell locomotion (Zhang et al., 2005) was used as the internal control gene because it is known to be moderately expressed in abundant levels in most cells, and it is found to have stable expression in hematopoietic cells (Matsuzaki et al., 2015). HL60 which is derived from a patient with acute promyelocytic leukemia having no fusion transcript (Collins, 1987), are useful to study on molecular mechanisms leukemic cells of the hematopoietic lineage (Collins, 1987). The B2M forward primer sequence has 5' GAGGCTATCCAGCGTACTCCAAAGAT 3' while the reverse has 5' TGAAACCCAGACACATAGCAATTCAGG 3'. The B2M PCR amplification produced $150 \mathrm{bp}$ PCR product.

As part of PCR optimization, samples were run on gel electrophoresis and specific melting temperature for each PCR product was checked using Rotor gene melt analysis software (Corbett
Research, Australia). All samples were run in triplicate.

Table 1. Clinical characteristics of cALL patients at diagnosis.

\begin{tabular}{|c|c|}
\hline Characteristics & Value (\%) \\
\hline $\begin{array}{l}\text { Gender-Number (\%) } \\
\text { Male } \\
\text { Female }\end{array}$ & $\begin{array}{l}46(63.89) \\
26(36.11) \\
\end{array}$ \\
\hline $\begin{array}{l}\text { Age group - Number (\%) } \\
<2 \mathrm{yr} \\
2-9 \mathrm{yr} \\
\geq 10 \mathrm{yr}\end{array}$ & $\begin{array}{l}10(13.89) \\
46(63.89) \\
16(22.22)\end{array}$ \\
\hline $\begin{array}{l}\text { Leukocyte count }\left(\times 10^{9} / L\right) \text { at diagnosis - } \\
\text { Number }(\%) \\
<20 \\
20-100 \\
>100\end{array}$ & $\begin{array}{l}36(50) \\
18(25) \\
18(25)\end{array}$ \\
\hline $\begin{array}{l}\text { Leukocyte count at diagnosis }\left(\times 10^{9} / \mathrm{L}\right) \\
\text { Median } \\
\text { Range }\end{array}$ & $\begin{array}{l}20.95 \\
0.6-708\end{array}$ \\
\hline $\begin{array}{l}\text { Blast count in bone marrow (percentage) } \\
\text { Median } \\
\text { Range }\end{array}$ & $\begin{array}{l}90 \\
30-90\end{array}$ \\
\hline $\begin{array}{l}\text { Hemoglobin }(g / L) \\
\text { Median } \\
\text { Range }\end{array}$ & $\begin{array}{l}8.3 \\
2.2-116\end{array}$ \\
\hline $\begin{array}{l}\text { Platelets }\left(\times 10^{9} / \mathrm{L}\right) \\
\text { Median } \\
\text { Range }\end{array}$ & $\begin{array}{l}43 \\
1.58-573\end{array}$ \\
\hline
\end{tabular}

\section{Relative real-time PCR quantification}

Relative quantification of TERF2 gene expression was calculated using the delta delta Ct method (Livak and Schmittgen, 2001). We tested the PCR efficiencies for TERF2 and B2M from a serially diluted RNA (from 1000ng to 0.1ng RNA). PCR efficiency from both genes was comparable having an efficiency of $90 \%$. Furthermore, we determined the amplification efficiencies of the two target sequences by subtracting $\mathrm{Ct}$ values of TERF2 and $\mathrm{Ct}$ values of B2M and the difference in $C t$ values was then plotted against the log values of the template amount. The slope of the resulting straight line was found to be $0.088 \quad(<0.1)$, indicating our amplification efficiencies were comparable and gene expression analysis can be used to perform delta-delta Ct method analysis.

Receiver operating characteristic curve analysis Receiver operating characteristic (ROC) curve 
analysis was used to determine TERF2 level that best discriminates between patients who achieved or failed day 33 remission. Only fifty-four samples were only included due to data insufficiency for the day 33 remission status. Patients who achieved remission were labeled as event $(n=0)$ and those who does not achieve remission were labeled as a non-event $(\mathrm{n}=1)$. The ROC curve was generated by using MedCalc ${ }^{\circledR}$ version 11.3.8.0.

\section{Kaplan-Meier estimation}

Kaplan-Meier estimation was used to evaluate the overall survival of the patients. Kaplan-Meier analysis was performed in 72 cALL patients (all subtypes) that were stratified accordingly following ROC curve analysis.

\section{Statistical analysis}

One-way ANOVA with Bonferroni correction was used to compare TERF2 gene expression values in cALL with various groups and TERF2 gene expression within cALL molecular subtypes. Univariate analysis using Chi-square test was performed to determine statistical links between biological and clinical parameters.

\section{RESULTS}

\section{TERF2 mRNA expression in childhood ALL}

We studied a total of 72 de novo cALL diagnostic bone marrow samples for TERF2 gene expression level. There was a broad spectrum of TERF2 expression, ranging from 0.0072 to 4.2575 (mean $=0.5736$, median $=0.5664$ ). TERF2 gene expression from diagnostic bone marrow samples was compared with normal bone marrow samples, other childhood hematological malignancies (CML and AML) and pediatric solid tumors. ANOVA one-way test shows significant differences between groups ( $\mathrm{p}$-value $=0.00053$ ), $\mathrm{p}<0.05$ (Figure 1). Post-hoc test between groups shows significant TERF2 expression in cALL compared with control samples $\mathrm{p}$-value $=0.00286, \mathrm{P}<0.05$; while comparisons with groups were insignificant. Further analysis of TERF2 expression between subtypes of cALL shows significant differences in TEL-AML subgroup compared to control samples with $\mathrm{p}$-value $=0.00023, \mathrm{p}<0.05$ as shown in Figure 2. Although lower expression was recorded in $B C R-A B L 1$ subtype in comparison to control, it is not-significant.

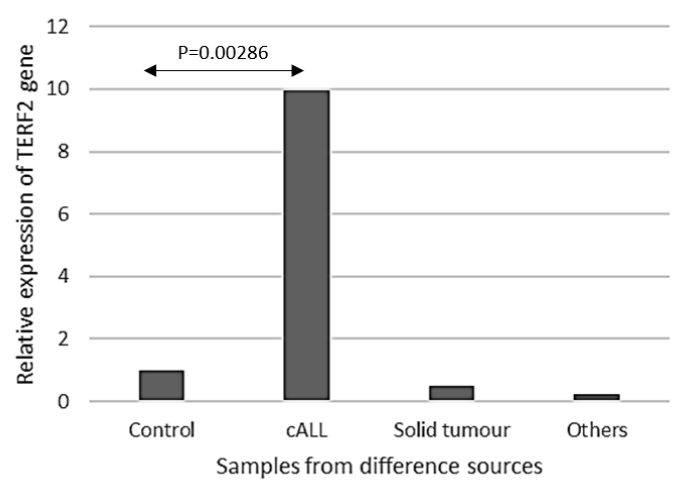

Figure 1. Bar graph showing means and standard error of relative expression of TERF2 in 94 samples from different groups. The x-axis refers to the samples from various groups whilst the $\mathrm{y}$ axis refers to relative expression of TERF2. ANOVA one-way test shows significant difference between groups $\mathrm{P}=0.00053, \mathrm{P}<0.05$ (Figure 1). Further analysis between childhood leukemia samples (cALL) subtypes shows significant differences in cALL compared to control which is non-cancerous bone marrow samples having $\mathrm{p}$-value $=0.00286, \mathrm{p}<0.05$. There is no significant difference between others (which comprises of CML and AML) and solid tumors with control.

\section{Prognostic significance of TERF2 $m R N A$ expression in cALL}

The cutoff point value was used to discriminate over-expression or under-expression of TERF2 by using ROC curve analysis (Figure 3). Following this, the area under the curve was determined with 0.663 having significance level of $\mathrm{p}$-value $=$ $0.0273(\mathrm{p}<0.05)(95 \%$ CI $0.521,0.786)$ and the cut off value generated was 0.3439 . Patients who have an expression less than 0.3439 were declared as TERF2 under-expression and over-expression for those who have higher expression than 0.3439 .

Kaplan-Meier analysis of relapse-free survival in 72 patients shows 17 out of 35 patients who under-expressed TERF2 and 14 patients $(82.35 \%)$ did not achieve clinical remission at day 33. In contrast, of 37 who over-expressed TERF2, 11 of them achieved clinical remission at day 33 $(29.73 \%)$. The result shows a better overall 
survival for cALL patients with TERF2 overexpression while poorer overall survival for under-expressed TERF2. Univariate analysis using Chi-square test was carried out to evaluate the relationship between TERF2 under and over- expression level with clinical parameters. We found that TERF2 gene expression was not associated with age, hyperleukocytosis, or risk groups (Table 2).

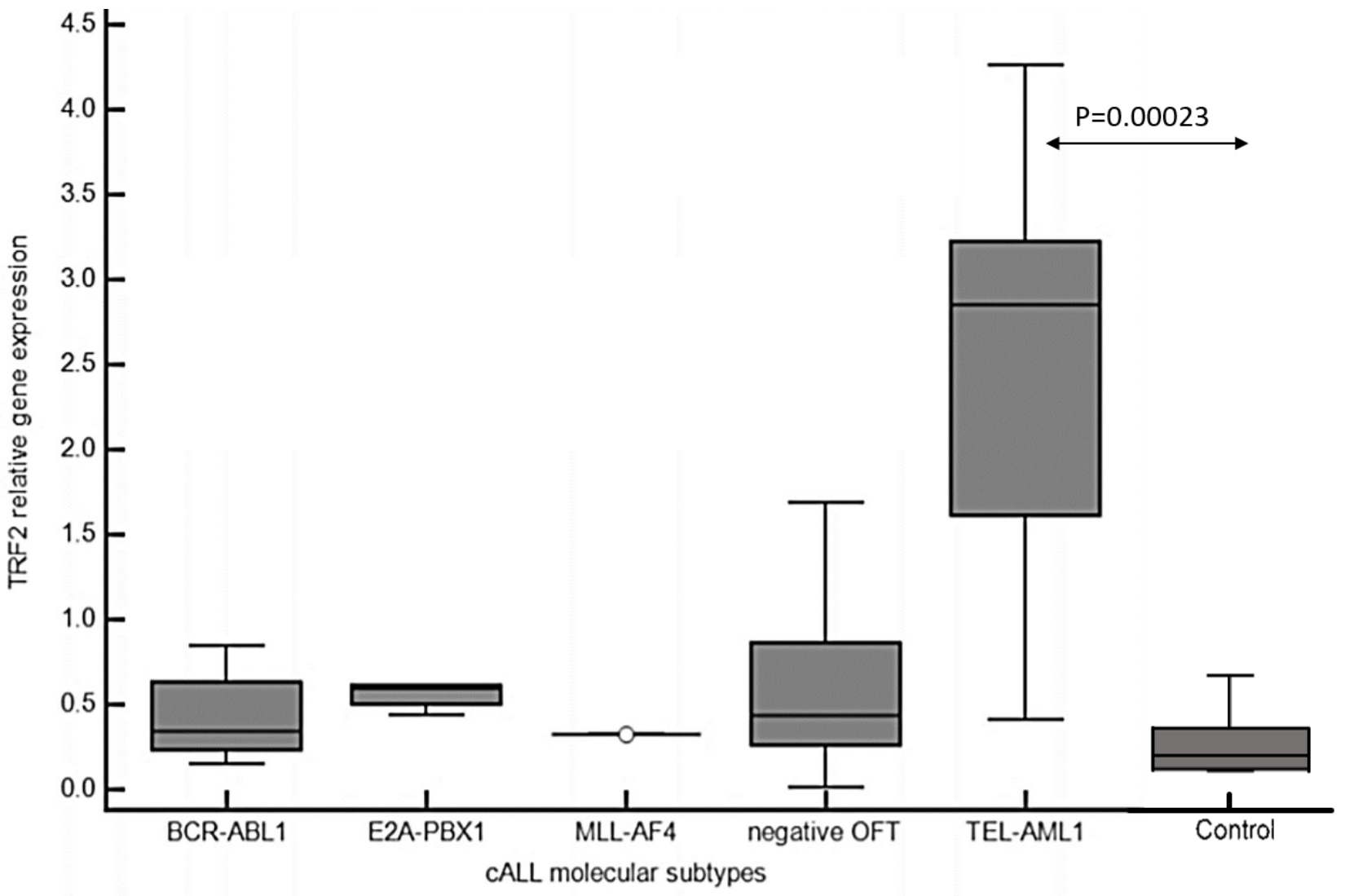

Figure 2. Shows box and whisker plot representation of relative fold of TERF2 expression in 72 diagnostic bone marrows in cALL with different molecular subtypes (TEL-AML1; $\mathrm{n}=11, B C R-A B L 1$; $\mathrm{n}=7, E 2 A-P B X 1 ; \mathrm{n}=4, M L L-A F 4 ; \mathrm{n}=1$ and negative OFT; $\mathrm{n}=49)$. Statistical analysis shows that TEL$A M L 1$ patients have significantly higher expression of TERF2 compared to control. Significant association was not found in BCR-ABL1 ( $>>0.05), E 2 A-P B X 1(\mathrm{p}>0.05), M L L-A F 4$ and negative OFT subgroups ( $\mathrm{p}>0.05)$. The median expression level of TERF2 in different subgroups was: $B C R-A B L, 0.344$; TEL-AML1, 2.848; E2A-PBX1, 0.591; MLL-AF4, 0.321 and those without any fusion transcripts, 0.435 .

Table 2. Table shows the evaluation of TERF2 relative gene expression.

\begin{tabular}{cccc}
\hline Clinical parameters & $\begin{array}{c}\text { TERF2 over- } \\
\text { expression (37) }\end{array}$ & $\begin{array}{c}\text { TERF2 under- } \\
\text { expression (17) }\end{array}$ & p-value \\
\hline Age $<2$ years & $29(29.41 \%)$ & $12(70.59 \%)$ & 0.7 \\
\hline $\begin{array}{c}\text { Leucocytosis }> \\
5 \times 10^{9} / \mathrm{L}\end{array}$ & $15(40.54 \%)$ & $6(35.29 \%)$ & 0.9 \\
\hline Poor risk & $3(8.1 \%)$ & $5(29.41 \%)$ & 0.09 \\
\hline Relapse & $6(16.22 \%)$ & $4(23.52 \%)$ & 0.7 \\
\hline
\end{tabular}

Evaluation of TERF2 relative gene expression with different clinical parameters (Age, leucocytosis, poor risk, relapse) by using univariate analysis. None of the parameters shows association with the TERF2 expressions. 


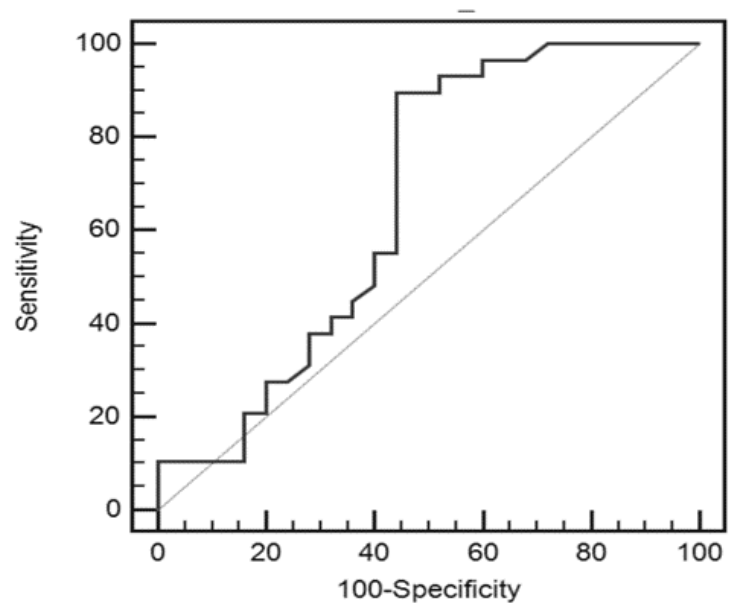

Figure 3. The cutoff point value used to discriminate over-expression or under-expression of TERF 2 by ROC curve analysis. The area under the curve was determined with 0.663 having significance level of $\mathrm{p}$-value $=0.0273(\mathrm{p}<0.05)$ (95\% CI $0.521,0.786)$ and the cut off value generated was 0.3439. Patients who have an expression less than 0.3439 were declared as TERF2 under-expression and over-expression for those who have higher expression than 0.3439 .

\section{DISCUSSION}

The relationship with telomere impairment and cancer has been well debated and discussed. It is known that shorten telomere contributes toward cancer initiation and progression. DNA binding proteins TERF2 bounds directly with double stranded telomere sequences and plays a crucial role for telomere end protection and helps in the t-loops conformation (Jones et al., 2012). Studies shows that expression level of shelterin protein complex like TERF2 are elevated and correlated with cancer progression in many cancers as compared to the non-noncancerous tissues. Our studies show found that TERF2 expression are significantly high in cancerous samples compared to the normal samples. Upregulation of TERF2 in malignant cells were well documented in previous publications (Biroccio et al., 2006; Oh et al., 2005; Nakanishi et al., 2003; Diehl et al., 2011; Nijjar et al., 2005; Dong et al., 2010; Benhamou et al., 2016). TERF2 over-expression that were reported in the lung, gastric, breast (Savage et al., 2007; Pellatt et al., 2013, Diehl et al., 2011), renal cancers (Chen et al., 2017; Pal et al., 2015), prostate (Kibel et al., 2016; Chen et al., 2017) and colorectal cancer (Aljarbou et al., 2018) might confer proliferative advantages to tumor cells (Kumar et al., 2018). Recent study also shows TERF2 occupancy at promoter were enriched in cells with short telomeres (Mukherjee et al., 2018).

Unlike other studies, our research focusses on investigation of TERF2 expression in the different molecular subgroups of cALL. Analysis of TERF2 expression in cALL subgroups shows significantly higher TERF2 expression in TELAML1 subgroups compared to control. TELAML1 subgroup of ALL generally presents with low or medium risk features and overall has a very good prognosis. We suggest that over-expression of TERF2 in TEL-AML1 would serve as a protective mechanism for the telomere from end to end fusion by preventing anaphase bridges from occurring and promoting chromosomal stability leading to the stable environment (Hartmann and Scherthan, 2005; Cookson and Laughton, 2009; Wang et al., 2018). With the presence of intact telomere maintenance function, TERF2 triggers normal apoptosis and DNA damage mechanism via ataxia-telangiectasia mutated (ATM) and p53 signalling pathway checkpoint (Maser and DePinho, 2002). TELAML1 is known as good prognostic molecular subgroup in cALL, hence this may suggests the role of TERF2 over-expression may enhance responsiveness to standard chemotherapy and patients achieve complete remission by day 33 (Subotnicu et al., 2017; Seeger et al., 2001).

Hypomethylation of promoter and exon 1 CpG islands of TERF2 may appear to be one of the critical epigenetic mechanisms by which TERF2 gene can be over-expressed. However, this is not the only mechanism involved in TERF2 regulation (Dong et al., 2010). In TEL-AML1 cells after it has been exposed to L-asparaginase, the genome-wide analysis revealed that TERF2 gene expression decreased significantly together with a panel of genes namely MCM3, MCM4, MCM5, CDC23 which are involved in cellular proliferation. (Lynch et al., 2008). Higher expressions of TERF2 in TEL-AML1 have been reported in (Yeoh et al., 2002; Ross et al., 2003; van Delft et al., 2005) which suggested that the gene protects the telomere end against senescence as most leukaemic cells have short telomeres (Ross 
et al., 2003). Another different study has observed the correlation between high TERF2 expression and longer life spans of advanced stage cervical cancer patients which suggests that TERF2 as an important factor in chromatin stability and survival (Ozden et al., 2014).

TERF2 is under-express in BCR-ABL1 patient cells. Although this is not significant in our present study due to low sample number, it may propose reason to why $B C R-A B L 1$ is often present with high-risk features and with poor prognosis during treatment. TERF2 underexpression will not be able to protect the telomere causing more severe complications to the chromosomes and genomic stability. The situation in BCR-ABL1 and MLL-AF4 cells becomes more complex as there is a high incidence of potential p53 pathway inactivation due to p53 mutation and MDM2 over-expression in these patients BCR-ABL1 (Marks et al., 1996). The resistance mechanism involving TERF2 and $B C R-A B L 1$ and MLL-AF4 fusions are yet to be discovered.

We managed to investigate TERF2 gene expression in a small cALL sample size. Larger sample size will be needed to confirm potent use of TERF2 as prognostic markers. To further understand TERF2 gene function and mechanism as well as its correlation with telomere, telomerase and telomere maintenance in subtypes of cALL, in depth in vitro model experiments will be needed in the future.

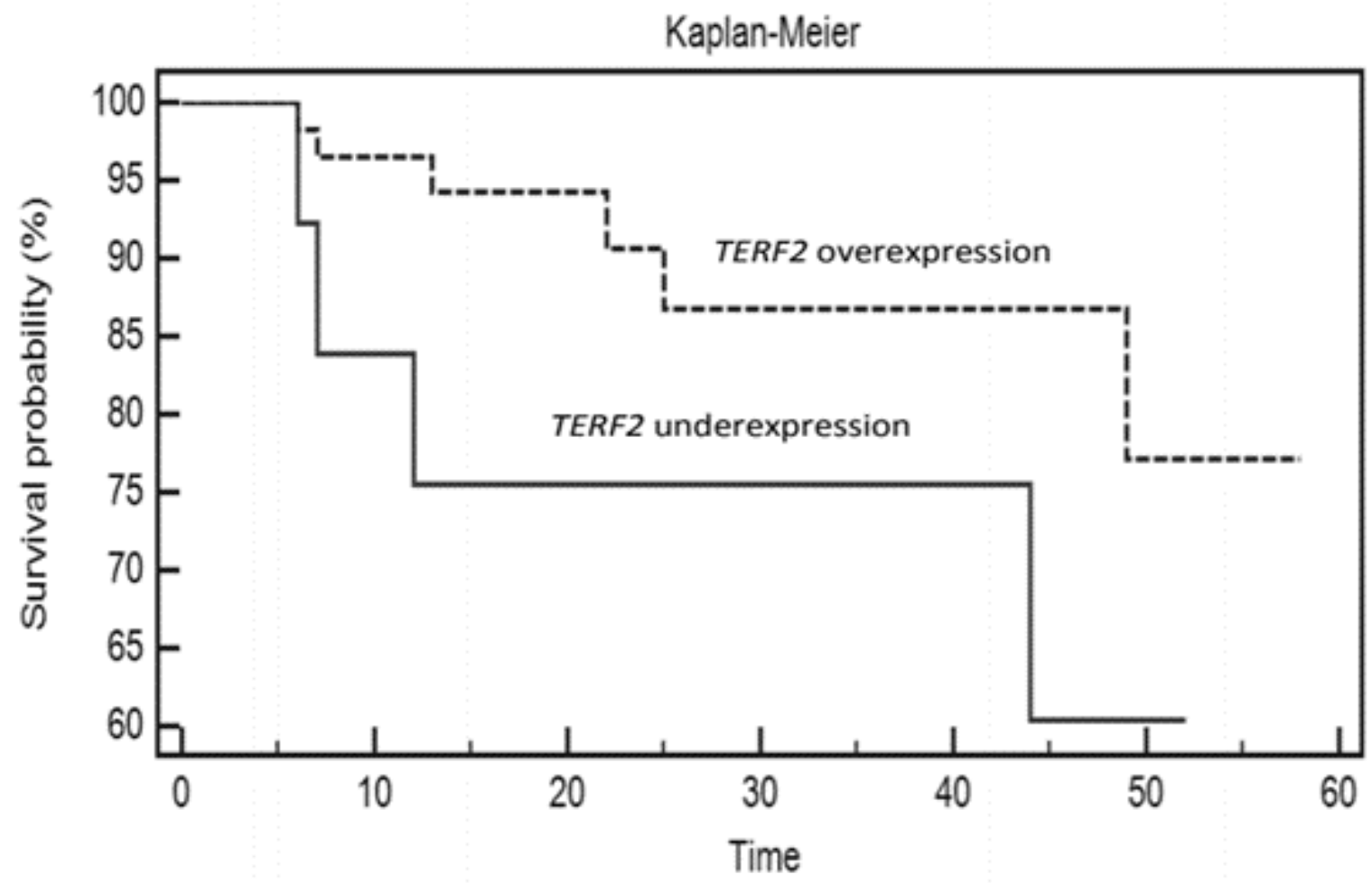

Figure 4. Kaplan-Meier analysis of relapse-free survival in 72 ALL patients. Patients were stratified according to the higher and lower expression of TERF2 in their diagnosis bone marrow samples taken at diagnosis. The $\mathrm{x}$-axis refers to the period of follow-up (months) and the y-axis refers to the proportion of patients. The dashed and dark lines refer to patients who over-expressed TERF2, or not respectively. Analysis shows a better survival for patients who over-express TERF2 comparatively with $\mathrm{p}<0.05$.

\section{CONCLUSION}

Over-expression of TERF2 is associated with good prognosis in cALL whilst under-expression is associated with poor prognosis in cALL patients. Measurement of TERF2 gene expression allows proper stratification of cALL subtypes into its respective prognostic indicator classification.

Telomere haemostasis has been significantly deregulated in cALL, and each molecular subtype 
have different deregulation of TERF2 gene expression. Our result suggests that TERF2 has a potential prognostic implication, which may taylor patients towards specific treatment decision and less invasive treatment regimen exposure. In addition, we hypothesize that TERF2 overexpression might have protective mechanism towards TEL-AML1 subtype. This may uncover the possibilities of telomere targeted therapies for cancer such as telomerase inhibitor. It is important to note that telomere haemostasis in cALL and adult might not be consistent due to the different disease behavior. Therefore, further investigation is needed to confirm the mechanism.

\section{ACKNOWLEDGEMENTS}

We want to thank The Malaysian National Cancer Council (MAKNA) for supporting this research. We also would like to thank Professor Dr Hany Ariffin for her clinical expertise.

\section{ETHICAL APPROVAL}

Approval for this project was obtained from the University of Malaya Medical Centre Ethics committee for both the leukemia (MEC 2006/481.01) and solid tumour (MEC 2006/510.7) components.

\section{REFERENCES}

Aljarbou, F., Almousa, N., Bazzi, M., Aldaihan, S., Alanazi, M., Alharbi, O., Almadi, M., Aljebreen, A. M., Azzam, N. A., \& Arafa, M. 2018. The expression of telomere-related proteins and DNA damage response and their association with telomere length in colorectal cancer in Saudi patients. PloS One 13: e0197154.

Avigad, S., Naumov, I., Ohali, A., Jeison, M., Berco, G. H., Mardoukh, J., Stark, B., Ash, S., Cohen, I. J., \& Meller, I. 2007. Short telomeres: a novel potential predictor of relapse in Ewing sarcoma. Clinical Cancer Research 13: 5777-5783.

Benhamou, Y., Picco, V., Raybaud, H., Sudaka, A., Chamorey, E., Brolih, S., Monteverde, M., Merlano, M., Nigro, C. L., \& Ambrosetti, D. 2016. Telomeric repeat-binding factor 2: a marker for survival and anti-EGFR efficacy in oral carcinoma. Oncotarget 7: 44236.

Bernal, A. \& Tusell, L. 2018. Telomeres: Implications for cancer development. International Journal of Molecular Sciences 19: 294.
Biroccio, A., Rizzo, A., Elli, R., Koering, C.-E., Belleville, A., Benassi, B., Leonetti, C., Stevens, M. F., D'incalci, M., \& Zupi, G. 2006. TRF2 inhibition triggers apoptosis and reduces tumourigenicity of human melanoma cells. European Journal of Cancer 42: 1881-1888.

Chen, W., Wang, Y., Li, F., Lin, W., Liang, Y., \& Ma, Z. 2017. Expression of telomere repeat binding factor 1 and TRF2 in prostate cancer and correlation with clinical parameters. BioMed Research International 2017.

Cho, Y.-U., Chi, H.-S., Park, C.-J., Jang, S., \& Seo, E.-J. 2012. Rapid detection of prognostically significant fusion transcripts in acute leukemia using simplified multiplex reverse transcription polymerase chain reaction. Journal of Korean Medical Science 27: 1155

Collins, S. J. 1987. The HL-60 promyelocytic leukemia cell line: proliferation, differentiation, and cellular oncogene expression.

Cookson, J. \& Laughton, C. 2009. The levels of telomere-binding proteins in human tumours and therapeutic implications. European Journal of Cancer 45: 536-550.

De Lange, T. 2005. Shelterin: the protein complex that shapes and safeguards human telomeres. Genes \& Development 19: 21002110.

Diehl, M. C., Idowu, M. O., Kimmelshue, K. N., York, T. P., Jackson-Cook, C. K., Turner, K. C., Holt, S. E. \& Elmore, L. W. 2011. Elevated TRF2 in advanced breast cancers with short telomeres. Breast Cancer Research and Treatment 127: 623-630.

Dong, W., Wang, L., Chen, X., Sun, P., \& Wu, Y. 2010. Upregulation and $\mathrm{CpG}$ island hypomethylation of the TRF2 gene in human gastric cancer. Digestive Diseases and Sciences 55: 997-1003.

Gandemer, V., Rio, A.-G., De Tayrac, M., Sibut, V., Mottier, S., Sunnaram, B. L., Henry, C., Monnier, A., Berthou, C., \& Le Gall, E. 2007. Five distinct biological processes and 14 differentially expressed genes characterize TEL/AML1positive leukemia. BMC Genomics 8: 385.

Hartmann, N. \& Scherthan, H. 2005. Characterization of the telomere complex, TERF1 and TERF2 genes in muntjac species with fusion karyotypes. Experimental Cell Research 306: 64-74.

Jafri, M. A., Ansari, S. A., Alqahtani, M. H., \& Shay, J. W. 2016. Roles of telomeres and telomerase in cancer, and advances in telomerase-targeted therapies. Genome Medicine 8: 69.

Jones, C. H., Pepper, C., \& Baird, D. M. 2012. Telomere dysfunction and its role in haematological cancer. British Journal of Haematology 156: 573-587.

Kaatsch, P. 2010. Epidemiology of childhood cancer. Cancer Treatment Reviews 36: 277-285.

Kaminker, P. G., Kim, S.-H., Taylor, R. D., Zebarjadian, Y., Funk, W. D., Morin, G. B., Yaswen, P., \& Campisi, J. 2001. TANK2, a new TRF1-associated poly (ADP-ribose) polymerase, causes rapid induction of cell death upon overexpression. Journal of Biological Chemistry 276: 35891 35899.

Karlseder, J., Smogorzewska, A., \& De Lange, T. 2002. Senescence induced by altered telomere state, not telomere loss. Science 295: 2446-2449.

Kibel, A. S., Ahn, J., Isikbay, M., Klim, A., Wu, W. S., Hayes, R. B., Isaacs, W. B., \& Daw, E. W. 2016. Genetic variants in cell cycle control pathway confer susceptibility to aggressive prostate carcinoma. The Prostate 76: 479-490.

Klapper, W., Qian, W., Schulte, C., \& Parwaresch, R. 2003. DNA damage transiently increases TRF2 mRNA expression and telomerase activity. Leukemia 17: 2007-2015.

Kumar, R., Khan, R., Gupta, N., Seth, T., Sharma, A., Kalaivani, M., \& Sharma, A. 2018. Identifying the biomarker potential of telomerase activity and shelterin complex molecule, 
telomeric repeat binding factor 2 (TERF2), in multiple myeloma. Leukemia \& Lymphoma 59: 1677-1689.

Lechel, A., Satyanarayana, A., Ju, Z., Plentz, R. R., Schaetzlein, S., Rudolph, C., Wilkens, L., Wiemann, S. U., Saretzki, G., \& Malek, N. P. 2005. The cellular level of telomere dysfunction determines induction of senescence or apoptosis in vivo. EMBO Reports 6: 275-281.

Lin, J., Countryman, P., Buncher, N., Kaur, P., E, L., Zhang, Y., Gibson, G., You, C., Watkins, S. C., \& Piehler, J. 2013. TRF1 and TRF2 use different mechanisms to find telomeric DNA but share a novel mechanism to search for protein partners at telomeres. Nucleic Acids Research 42: 2493-2504.

Livak, K. J. \& Schmittgen, T. D. 2001. Analysis of relative gene expression data using real-time quantitative PCR and the 2$\Delta \Delta$ CT method. Methods 25: 402-408.

Locatelli, F., Schrappe, M., Bernardo, M. E., \& Rutella, S. 2012. How I treat relapsed childhood acute lymphoblastic leukemia. Blood 120(14): 2807-2816.

Lynch, M., Sung, W., Morris, K., Coffey, N., Landry, C. R., Dopman, E. B., Dickinson, W. J., Okamoto, K., Kulkarni, S., \& Hartl, D. L. 2008. A genome-wide view of the spectrum of spontaneous mutations in yeast. Proceedings of the National Academy of Sciences 105: 9272-9277.

Marks, D. I., Kurz, B. W., Link, M. P., Ng, E., Shuster, J. J., Lauer, S. J., Brodsky, I., \& Haines, D. S. 1996. High incidence of potential p53 inactivation in poor outcome childhood acute lymphoblastic leukemia at diagnosis.

Martínez, P. \& Blasco, M. A. 2017. Telomere-driven diseases and telomere-targeting therapies. Journal of Cell Biology 216: 875887.

Maser, R. S. \& Depinho, R. A. 2002. Connecting chromosomes, crisis, and cancer. Science 297: 565-569.

Matsuzaki, Y., Umemoto, T., Tanaka, Y., Okano, T. \& Yamato, M. 2015. $\beta 2$-Microglobulin is an appropriate reference gene for RT-PCR-based gene expression analysis of hematopoietic stem cells. Regenerative Therapy 1: 91-97.

Mukherjee, A. K., Sharma, S., Sengupta, S., Saha, D., Kumar, P., Hussain, T., Srivastava, V., Roy, S. D., Shay, J. W., \& Chowdhury, S. 2018. Telomere length-dependent transcription and epigenetic modifications in promoters remote from telomere ends. PLoS Genetics 14: e1007782.

Nakanishi, K., Kawai, T., Kumaki, F., Hiroi, S., Mukai, M., Ikeda, E., Koering, C. E., \& Gilson, E. 2003. Expression of mRNAs for telomeric repeat binding factor (TRF)-1 and TRF2 in atypical adenomatous hyperplasia and adenocarcinoma of the lung. Clinical Cancer Research 9: 11051111.

Neidle, S. \& Parkinson, G. N. 2003. The structure of telomeric DNA. Current Opinion in Structural Biology, 13: 275-283.

Nijjar, T., Bassett, E., Garbe, J., Takenaka, Y., Stampfer, M. R., Gilley, D., \& Yaswen, P. 2005. Accumulation and altered localization of telomere-associated protein TRF2 in immortally transformed and tumor-derived human breast cells. Oncogene 24: 3369.

Oh, B.-K., Kim, Y.-J., Park, C., \& Park, Y. N. 2005. Up-regulation of telomere-binding proteins, TRF1, TRF2, and TIN2 is related to telomere shortening during human multistep hepatocarcinogenesis. The American Journal of Pathology 166: 73-80.

Ozden, S., Tiber, P. M., Ozgen, Z., Ozyurt, H., Serakinci, N., \& Orun, O. 2014. Expression of TRF2 and its prognostic relevance in advanced stage cervical cancer patients. Biological Research 47: 1-7.

Pal, D., Sharma, U., Singh, S. K., Kakkar, N., \& Prasad, R. 2015. Over-expression of telomere binding factors (TRF1 \& TRF2) in renal cell carcinoma and their inhibition by using
SiRNA induce apoptosis, reduce cell proliferation and migration invitro. PloS One 10: e0115651.

Pellatt, A. J., Wolff, R. K., Torres-Mejia, G., John, E. M., Herrick, J. S., Lundgreen, A., Baumgartner, K. B., Giuliano, A. R., Hines, L. M., \& Fejerman, L. 2013. Telomere length, telomere-related genes, and breast cancer risk: the breast cancer health disparities study. Genes, Chromosomes and Cancer 52: 595-609.

Ross, M. E., Zhou, X., Song, G., Shurtleff, S. A., Girtman, K., Williams, W. K., Liu, H.-C., Mahfouz, R., Raimondi, S. C., \& Lenny, N. 2003. Classification of pediatric acute lymphoblastic leukemia by gene expression profiling. Blood 102: 2951-2959.

Savage, S., Chanock, S., Lissowska, J., Brinton, L., Richesson, D., Peplonska, B., Bardin-Mikolajczak, A., Zatonski, W., Szeszenia-Dabrowska, N. \& Garcia-Closas, M. 2007. Genetic variation in five genes important in telomere biology and risk for breast cancer. British Journal of Cancer 97: 832-836.

Seeger, K., Kreuzer, K.-A., Lass, U., Taube, T., Buchwald, D., Eckert, C., Körner, G., Schmidt, C.-A., \& Henze, G. 2001. Molecular quantification of response to therapy and remission status in TEL-AML1-positive childhood ALL by real-time reverse transcription polymerase chain reaction. Cancer Research 61: 2517-2522.

Stansel, R. M., De Lange, T., \& Griffith, J. D. 2001. T-loop assembly in vitro involves binding of TRF2 near the $3^{\prime}$ telomeric overhang. The EMBO Journal 20: 5532-5540.

Subotnicu, M., Ivanov, A., Ivanov, I., Mocanu, A., Dumitras, S., Antonela, C., Schmidt, M., Rusu, C., \& Miron, I. 2017. P378 Molecular diagnostic markers for childhood acute leukaemia-a single centre experience. BMJ Publishing Group Ltd.

Van Delft, F. W., Bellotti, T., Luo, Z., Jones, L. K., Patel, N., Yiannikouris, O., Hill, A. S., Hubank, M., Kempski, H., \& Fletcher, D. 2005. Prospective gene expression analysis accurately subtypes acute leukaemia in children and establishes a commonality between hyperdiploidy and $\mathrm{t}(12$; 21) in acute lymphoblastic leukaemia. British Journal of Haematology 130: 26-35.

Van Steensel, B., Smogorzewska, A. \& De Lange, T. 1998. TRF2 protects human telomeres from end-to-end fusions. Cell 92 : 401-413.

Wang, L., Tu, Z., Liu, C., Liu, H., Kaldis, P., Chen, Z., \& Li, W. 2018. Dual roles of TRF1 in tethering telomeres to the nuclear envelope and protecting them from fusion during meiosis. Cell Death \& Differentiation 25: 1174.

Wang, R. C., Smogorzewska, A., \& De Lange, T. 2004. Homologous recombination generates T-loop-sized deletions at human telomeres. Cell 119: 355-368.

Yeoh, E.-J., Ross, M. E., Shurtleff, S. A., Williams, W. K., Patel, D., Mahfouz, R., Behm, F. G., Raimondi, S. C., Relling, M. V., \& Patel, A. 2002. Classification, subtype discovery, and prediction of outcome in pediatric acute lymphoblastic leukemia by gene expression profiling. Cancer Cell 1: 133143.

Zhang, X., Ding, L., \& Sandford, A. J. 2005. Selection of reference genes for gene expression studies in human neutrophils by real-time PCR. BMC Molecular Biology 6: 1-7. 